\title{
Fungicide Resistance of Two Species of Alternaria from Potato in the Columbia Basin of Washington
}

\author{
Lydia Tymon and Dennis A. Johnson, Department of Plant Pathology, Washington State University, Pullman, WA 99163
}

\begin{abstract}
Tymon, L., and Johnson, D. A. 2014. Fungicide resistance of two species of Alternaria from potato in the Columbia Basin of Washington. Plant Dis. 98:1648-1653.

Fungicides are extensively used in the Columbia Basin of Washington in an effort to manage early blight and brown spot on potato caused by Alternaria solani and A. alternata, respectively. Azoxystrobin and boscalid interfere with cellular respiration, and fungicide resistance is expected to occur in fungal populations due to the narrow modes of action dictated by each fungicide. The objective of this research was to assess A. solani and A. alternata populations in the Columbia Basin of Washington for azoxystrobin and boscalid resistance by initially screening isolates at a threshold concentration using mycelial growth and spore germination. Fifty isolates of $A$. solani and 58 of A. alternata were randomly selected for screening from 671 isolates collected from potato in the Columbia Basin from 2009 to 2011. Screening at a threshold concentration was done to estimate the range of fungicide resistance within the populations of $A$. solani and A. alternata in the region. Resistance of five isolates that differed in sensitivity to azoxystrobin and boscalid were then assessed for mycelial growth and spore germination at three fungicide concentrations in order to deter-

mine where rates were no longer effective. A. solani mycelial growth ratios and percent spore germination on azoxystrobin-amended media did not change from 2010 to 2011. A slight decrease in resistance of mycelial growth to azoxystrobin was exhibited among A. alternata isolates collected between 2010 and 2011. No change in sensitivity to azoxystrobin was observed in mycelial growth ratios among A. alternata isolates collected between 2010 and 2011. Resistance to boscalid by $A$. solani increased as indicated by a significant increase in mean mycelial growth ratio from 2010 to 2011, whereas A. alternata showed no change. Spore germination of $A$. solani was less at $100 \mu \mathrm{g} / \mathrm{ml}$ than at 1 or $10 \mu \mathrm{g} / \mathrm{ml}$ azoxystrobin. Spore germination of $A$. alternata did not differ among 1,10 , or $100 \mu \mathrm{g} / \mathrm{ml}$ azoxystrobin. Spore germination of $A$. solani and A. alternata did not differ among $0.5,5$, or $50 \mu \mathrm{g} / \mathrm{ml}$ boscalid. Resistance to azoxystrobin and boscalid in A. solani and $A$. alternata populations was shown to be present in the Columbia Basin and will likely become widespread with continued used of site-specific fungicides.
\end{abstract}

The Columbia Basin of south-central Washington and northcentral Oregon is a major potato-growing region of the world. Potatoes are grown on more than 80,000 ha annually, with mean tuber yields exceeding $74 \mathrm{MT} / \mathrm{ha}$ in 2012 (30). The region is isolated and bordered by mountains, and has a semi-arid environment, and potatoes are irrigated by center pivot systems (11). Approximately $85 \%$ of the production of the region is in Washington State. Potato is Washington State's third largest crop, with an estimated annual production of $7.7 \times 10^{13} \mathrm{~kg}$ of potatoes and a farm gate value of approximately $\$ 690$ million (30).

Potatoes are susceptible to a number of diseases that are managed with fungicides and crop rotation. Early blight, caused by Alternaria solani, and brown spot, caused by A. alternata, are two such diseases. Both diseases result in lesions on foliage and tubers. Yield losses can occur when infection by $A$. solani takes place before or while tubers are bulking (29). Yield losses due to A. alternata have not been documented. Crop rotations of at least 3 years out of potatoes are recommended for control of early blight (22). In the Columbia Basin, potato fields are often rotated with alfalfa, bean, corn, onion, and small grains $(22,23)$. Fungicides are the primary means of disease control since there are no potato cultivars that are completely resistant to these pathogens.

Approximately two to three fungicide applications are made during the growing season to manage early blight in the Columbia Basin of Washington, with application numbers as high as 10 in other regions (27). Effective control was obtained in Pennsylvania with seven to eight applications when applications were started

Corresponding author: Lydia Tymon,

E-mail: lydia.tymon@email.wsu.edu

Accepted for publication 10 May 2014.

http://dx.doi.org/10.1094/PDIS-12-13-1199-RE

(c) 2014 The American Phytopathological Society approximately 6 to 7 weeks after planting (6). Several fungicides used to manage Phytophthora infestans also reduce early blight severity, and management for both diseases is often coupled. The number of fungicide applications on late-season potatoes targeted for late blight control in the Columbia Basin ranged from 5 to 12 during 1998 , with an average cost of approximately $\$ 159.00$ per acre (\$64.33/ha) (12).

Broad-spectrum fungicides are used for both late blight and early blight, and the benefit of these fungicides is that resistance has not been observed in spite of frequent and prolonged use. A switch over the last two decades has occurred from broad spectrum to narrow spectrum fungicides to reduce potential negative effects on human health and the environment (21). Fungicide resistance is a concern when managing crops, especially when the fungicide affects a single site and is repeatedly used $(8,10)$.

Two narrow spectrum fungicides used in the Columbia Basin are azoxystrobin and boscalid. Azoxystrobin is a strobilurin, which are quinone outside inhibitors (QoI) that inhibit cellular respiration by interfering with the electron transport chain in the mitochondria. These fungicides bind to the quinone outside binding site of cytochrome $b(4,26)$. The binding of this site prevents the transfer of electrons from cytochrome $\mathrm{b}$ to cytochrome $\mathrm{c}_{1}$, which prevents the production of adenosine triphosphate (ATP) (4). This group of fungicides also includes pyraclostrobin and trifloxystrobin, and has exhibited efficacy over a wide range of fungi. Resistance to QoI fungicides was first recorded on Blumeria graminis infecting wheat (25) and has since been documented in other fungi such as Colletotrichum graminicola (3), Ascochyta rabei (31), and Alternaria sp. (15).

Boscalid is a carboximide fungicide that also disrupts cellular respiration. The target of boscalid is the succinate ubiquinone oxidoreductase of complex II (2). Interference with this protein prevents the reduction of quinine. Resistance to boscalid has been observed in multiple fungi and crop systems, such as $A$. alternata on pistachio (1), Botrytis cinerea on apple (14), and Podosphaera xanthii on cucumber (17). Resistance to boscalid is 
due to mutation that occurs in all three of the subunit coding regions (2).

Resistance to azoxystrobin and boscalid has been detected in populations of $A$. solani on potato in the Midwest $(21,25)$ and in southern Idaho (9). A. alternata resistance to azoxystrobin and boscalid has been reported on pistachio in California $(1,13,15)$ and in southern Idaho (9). Fungicide resistance of Alternaria species to azoxystrobin or boscalid on potato has not been reported in the Columbia Basin. Knowledge of the presence of resistance to these fungicides in the Alternaria populations in the Columbia Basin would be important in designing disease management strategies for the region. The objective of this research was to assess $A$. solani and A. alternata populations in the Columbia Basin of Washington for azoxystrobin and boscalid resistance by initially screening isolates using mycelial growth at a threshold concentration and then further assessing a few, selected isolates for mycelial growth and spore germination at three concentrations of the two fungicides. Screening at the threshold concentration was done in an attempt to capture the range of fungicide resistance within the populations of $A$. solani and A. alternata in the region and to reduce the number of isolates needed for detailed assessment.

\section{Materials and Methods}

Potato foliage with lesions was collected from commercial potato fields in the Columbia Basin of Washington in 2009 through 2011. Foliage was placed in plastic bags, sealed, and transported to the laboratory in Pullman, WA. Potato leaflets with lesions were surface-disinfested by dipping in $70 \%$ ethanol for 3 to $5 \mathrm{~s}$. Leaflets were blotted with paper towels and air-dried. Lesion margins were then excised and plated on a modified potato dextrose agar (mPDA; 20 g/liter Difco Bactoagar, 1 g/liter Difco PDA, 6 ml/liter $95 \%$ ethanol). A total of 524 A. alternata and $147 \mathrm{~A}$. solani isolates were collected between 2009 and 2011. Single spore isolates were obtained from single lesions from single leaflets and grown on mPDA under 24-h lights at 21 to $23^{\circ} \mathrm{C}$. Isolates were grown on mPDA for 7 to 10 days under continuous fluorescent lights to prepare material for mycelial growth and spore germination assays.

Stock solutions of technical grade azoxystrobin (95.3\% active ingredient; Syngenta Crop Protection Inc., Greensboro, NC) and boscalid ( $99 \%$ active ingredient; BASF Corporation, Research Triangle Park, NC) were prepared in acetone at $10,000 \mu \mathrm{g} / \mathrm{ml}$ and $5,000 \mu \mathrm{g} / \mathrm{ml}$, respectively. Azoxystrobin and boscalid were added to $1.5 \%$ Difco water agar (BD, Franklin Lakes, NJ). Salicylhydroxamic acid (SHAM) was added to media to block the use of an alternate pathway for cellular respiration. A $100 \mathrm{mg} / \mathrm{ml}$ stock solution of SHAM was prepared in methanol and added to all fungicide-amended media $(1,21)$. The final concentration of SHAM was $100 \mu \mathrm{g} / \mathrm{ml}$. Control plates were amended with acetone and SHAM, where concentrations of acetone and methanol were at $0.1 \%$ $\mathrm{vol} / \mathrm{vol}$. Media was also amended with 1,10 , and $100 \mu \mathrm{g} / \mathrm{ml}$ of azoxystrobin. Media was amended with $0.5,5$, and $50 \mu \mathrm{g} / \mathrm{ml}$ of boscalid for final fungicide concentrations.

Assessment of fungicide resistance at a threshold concentration. A. solani and A. alternata were evaluated for fungicide resistance using mycelial growth and spore germination on water agar amended with azoxystrobin at a fungicide concentration of $100 \mu \mathrm{g} / \mathrm{ml}$ and boscalid at a concentration of $50 \mu \mathrm{g} / \mathrm{ml}$. Threshold concentrations were concentrations used in previous studies $(1,21)$. Fungicide resistance was determined for 50 isolates of $A$. solani and 58 isolates of $A$. alternata that were originally collected from potato in the Pacific Northwest.

For mycelial growth, spores were removed from media by gently scraping the media surface with a rubber spatula. Plates were washed with sterile, distilled water. A 6-mm-diameter plug was excised using a cork borer, and plugs were then plated top down onto fungicide amended water agar, and plates were maintained in the lab at 21 to $23^{\circ} \mathrm{C}$ under $24-\mathrm{h}$ fluorescent lights. Plates were arranged in a completely randomized design with two replicates per trial. The experiment was done twice.
Colonies were measured in two perpendicular directions at 3,5, and 7 days postplating. Colony area was determined by multiplying the measurements minus the diameter of the agar plug. Area under the growth progress curve (AUGPC) was calculated using the colony area over time for each isolate. Mycelial growth ratio was calculated by dividing AUGPC for each isolate on the fungicide-amended plate by the AUGPC of the control. Values closer to 1 indicated greater resistance, while values closer to 0 indicated greater sensitivity. A value of 0.5 or greater, or where mycelial growth was reduced by no more than half in comparison to the control, was selected as the boundary to indicate fungicide resistance. Isolates with mycelial growth ratios greater than 0.5 would have an $\mathrm{EC}_{50}$ greater than the threshold concentration of the fungicide. Mycelial growth ratios were used for statistical analyses.

In preparation for spore germination assessment, spores were gently scraped from media using a sterile scalpel and mixed into $1.5 \mathrm{ml}$ of sterile distilled water. One drop of Tween-20 (Thermo Scientific, Rockford, IL) was added to the suspension in order to prevent spore aggregation. The suspension was filtered through three layers of sterile cheesecloth and quantified using a haemocytometer. A. solani spore suspensions were adjusted to $10^{3}$ spores $/ \mathrm{ml}$, and A. alternata suspensions were adjusted to $10^{4}$ spores $/ \mathrm{ml}$. One hundred fifty microliters of the spore suspension was spread onto fungicide-amended plates. Plates were placed in the dark at 21 to $23^{\circ} \mathrm{C}$, and after $24 \mathrm{~h}$ the spore germination of 100 spores was assessed using a compound microscope. Germination was defined as the presences of a germ tube at least half the length of the spore, or if multiple germ tubes were present on a single spore. Plates were arranged in a completely randomized design with two replicates per trial. The experiment was repeated on a second date.

Fungicide concentration analysis. Mycelial growth and spore germination of five selected isolates were evaluated at three concentrations of azoxystrobin and boscalid to determine where rates were no longer effective. A subsample of two isolates of $A$. solani and three of A. alternata was selected for the assay based on mycelial growth ratios and selected isolates (Table 1). The isolates exhibited high sensitivity or resistance to either azoxystrobin or boscalid; one isolate of A. alternata exhibited resistance to both fungicides (Table 1). While using only five isolates cannot capture the full range of fungicide resistance that exists in the Columbia Basin, they were selected to instead evaluate the extreme ranges of sensitivity and resistance to these fungicides. Concentrations for azoxystrobin were 1,10 , and $100 \mu \mathrm{g} / \mathrm{ml}$ and for boscalid were 0.5 , 5 , and $50 \mu \mathrm{g} / \mathrm{ml}$.

Data analysis. Data for mycelial growth and spore germination were subjected to analysis of variance (ANOVA) using SAS Proc GLM (Release 9.2, SAS Institute Inc., Cary, NC). Trials that were not significantly different from each other were combined. Popula-

Table 1. Species, previous fungicides applied to field of collection, and mycelial growth ratios at the threshold concentrations of fungicides of five Alternaria isolates selected to evaluate where fungicide rates were no longer effective

\begin{tabular}{|c|c|c|c|}
\hline \multirow{3}{*}{$\begin{array}{l}\text { Species } \\
\text { Isolate }\end{array}$} & \multirow{3}{*}{$\begin{array}{l}\text { Fungicides } \\
\text { applied }^{\mathbf{y}}\end{array}$} & \multirow{2}{*}{\multicolumn{2}{|c|}{$\begin{array}{c}\text { Fungicide threshold test } \\
\text { Mycelial growth ratio }\end{array}$}} \\
\hline & & & \\
\hline & & Azoxystrobinz & Boscalid $^{\mathrm{z}}$ \\
\hline \multicolumn{4}{|l|}{ A. solani } \\
\hline AS10_95 & None & $0.2(\mathrm{~S})$ & $0.7(\mathrm{R})$ \\
\hline AS11_52 & None & $0.3(\mathrm{~S})$ & $0.2(\mathrm{~S})$ \\
\hline \multicolumn{4}{|l|}{ A. alternata } \\
\hline AA10_28 & $\mathrm{A}+\mathrm{D} / \mathrm{C} / \mathrm{F} / \mathrm{D}$ & $0.5(\mathrm{R})$ & $0.5(\mathrm{R})$ \\
\hline AA10_06 & $\mathrm{A}+\mathrm{D} / \mathrm{C} / \mathrm{F} / \mathrm{D}$ & 0.4 (MS) & $0.5(\mathrm{R})$ \\
\hline AA10_42 & $\mathrm{A}+\mathrm{D} / \mathrm{C} / \mathrm{F} / \mathrm{D}$ & $0.5(\mathrm{R})$ & $0.1(\mathrm{~S})$ \\
\hline
\end{tabular}

y Azxoystrobin + difenoconazole (A+D), chlorothalonil $(C)$, fluazinam $(F)$, difenoconazole (D).

${ }^{\mathrm{z}}$ Isolate exhibits resistance to fungicide (R), isolate exhibits moderate sensitivity to fungicide (MS), or isolate exhibits sensitivity to fungicide (S). 
tion mean, weighted mean, median, standard deviation, standard error, and effect size were used to characterize populations of $A$. solani and A. alternata. Weighted means were obtained by first multiplying the number of isolates with each mycelial growth ratio value by the mycelial growth ratio. The mean of the values was then calculated. Cohen's $d$, or effect size, was used to assess the biological significance of the treatment by quantifying the overlap between the treatment and control distributions (19). Larger effect size values correspond to smaller overlaps in distributions. Values of 0.20 indicate a small effect (or large overlap in distributions), of 0.50 indicate a medium effect, and of 0.8 or greater indicate a large effect (7). Cohen's $d$ was calculated as follows:

$$
d=\left(m_{2}-m_{1}\right) / s_{\text {pooled }}
$$

where $m_{1}=$ mean of the control, $m_{2}=$ mean of the treatment, and $s_{\text {pooled }}$ is the pooled standard deviation $(19,26) . s_{\text {pooled }}$ was calculated as follows:

$$
s_{\text {pooled }}=\sqrt{ }\left(n_{2}-1\right) s_{2}{ }_{2}+\left(n_{1}-1\right) s^{2}{ }_{1} / n_{1}+n_{2}-2
$$

where $n=$ sample size and $s^{2}=$ variance. Confidence intervals were calculated as follows, where:

$$
\begin{gathered}
\sigma[d]=\sqrt{ }\left(n_{1}+n_{2}\right) /\left(n_{1} * n_{2}\right)+d^{2} / 2\left(n_{1}+n_{2}\right) \\
\text { and }[d+(1.96 * \sigma[d]), d-(1.96 * \sigma[d])]
\end{gathered}
$$

\section{Results}

Assessment of fungicide resistance at a threshold concentration. Mycelial growth ratios for $A$. solani on azoxystrobin plates at a threshold concentration ranged between 0.10 and 0.40 , with a weighted mean mycelial growth ratio of 0.19 (Fig. 1, Table 2). The population mode for mycelial growth ratio was 0.2 with 17 of 50 isolates in that category. The maximum mycelial growth ratio of 0.40 for one isolate was below the boundary of 0.5 that differenti-

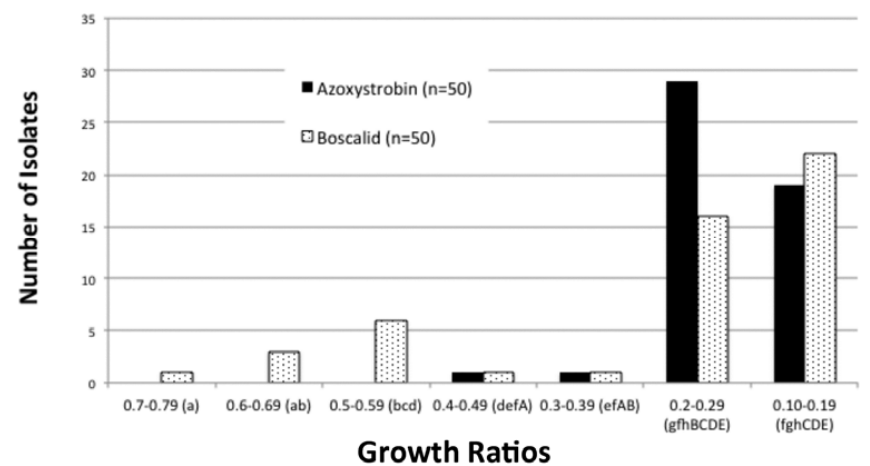

Fig. 1. Mycelial growth ratios for Alternaria solani on azoxystrobin $(100 \mu \mathrm{g} / \mathrm{ml})$ and boscalid ( $50 \mu \mathrm{g} / \mathrm{ml})$ amended media. Mycelial growth ratio was calculated and used for statistical analyses by dividing area under the growth progress curve (AUGPC) for each isolate on the fungicide amended plate by the AUGPC of the control. Values closer to 1 indicate greater resistance while values closer to 0 indicate greater sensitivity. $A B C$ Values indicate significance among isolates grown on azoxystrobin amended plates at $P=0.05$. abc Values indicate significance among isolates grown on boscalid amended plates at $P=0.05$. ated fungicide resistance. The effect size for A. solani grown on azoxystrobin was 4.4.

Mycelial growth ratios for $A$. solani at the threshold concentration of boscalid ranged between 0.10 and 0.76 with a weighted mean of 0.25 . The population mode for mycelial growth ratio was 0.20 with 15 of 50 isolates. Ten isolates exhibited moderate to high resistance with mycelial growth ratios above 0.5 . One isolate had a maximum mycelial growth ratio of 0.76 . The effect size for $A$. solani on boscalid plates was 2.8 .

Mycelial growth ratios for A. alternata at the threshold concentration of azoxystrobin ranged between 0.20 and 0.50 with a weighted mean mycelial growth ratio of 0.36 (Fig. 2, Table 2). The population mode was 0.30 with 14 of 50 isolates in that category. The effect size for A. alternata on azoxystrobin was 3.5.

Mycelial growth ratios for A. alternata at the threshold concentration of boscalid ranged between 0.05 and 0.53 with a weighted mean of 0.15 . The population mode was 0.1 , with 30 of 50 isolates in that category. The effect size for A. alternata on boscalid was 4.7.

Mean mycelial growth ratio and percent spore germination on azoxystrobin of $A$. alternata isolates collected in 2010 was significantly greater $(P<0.0001)$ than $A$. solani isolates collected in 2010 (Table 3 ). Mean mycelial growth ratio was 0.36 and percent spore germination was 0.73 for the A. alternata isolates. Mean mycelial growth ratio for the $A$. solani isolates was 0.20 and percent spore germination was 0.50 . Mean mycelial growth ratio of A. alternata isolates collected in 2011 was 0.33 and was significantly greater $(P$ $<0.0001)$ than that of $A$. solani isolates collected in 2011. Mean mycelial growth ratio for $A$. solani isolates was 0.21 . There was no significant difference $(P=0.22)$ between values for percent spore germination of $A$. alternata and $A$. solani isolates collected in 2011 on azoxystrobin. While mean mycelial growth ratio and percent spore germination of A. alternata isolates collected in 2010 on

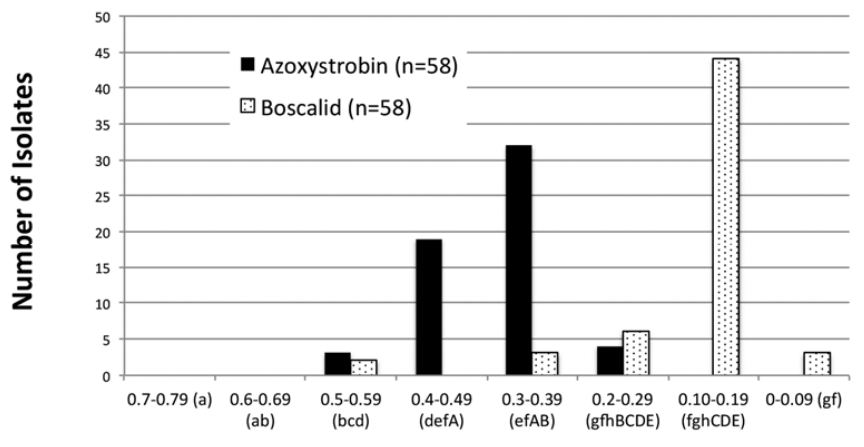

Growth Ratios

Fig. 2. Mycelial growth ratios for Alternaria alternata on azoxystrobin $(100 \mu \mathrm{g} / \mathrm{ml})$ and boscalid $(50 \mu \mathrm{g} / \mathrm{ml})$ amended media. Mycelial growth ratio was calculated and used for statistical analyses by dividing area under the growth progress curve (AUGPC) for each isolate on the fungicide-amended plate by the AUGPC of the control. Values closer to 1 indicate greater resistance while values closer to 0 indicate greater sensitivity. $A B C$ Values indicate significance among isolates grown on azoxystrobin amended plates at $P=0.05$. abc Values indicate significance

\begin{tabular}{|c|c|c|c|c|c|c|c|}
\hline & Mean & Weighted mean & Median & Std. dev. & Std. error & Effect size $^{y}$ & $\begin{array}{c}\text { Confidence } \\
\text { interval }^{\mathbf{z}}\end{array}$ \\
\hline \multicolumn{8}{|l|}{ A. alternata } \\
\hline Azoxystrobin & 0.35 & 0.36 & 0.34 & 0.09 & 0.01 & 3.5 & {$[3.1,3.9]$} \\
\hline Boscalid & 0.23 & 0.25 & 0.19 & 0.16 & 0.02 & 4.7 & {$[4.2,5.3]$} \\
\hline \multicolumn{8}{|l|}{ A. solani } \\
\hline Azoxystrobin & 0.22 & 0.19 & 0.22 & 0.08 & 0.01 & 4.4 & {$[3.9,4.9]$} \\
\hline Boscalid & 0.34 & 0.25 & 0.28 & 0.22 & 0.03 & 2.8 & {$[2.4,3.2]$} \\
\hline
\end{tabular}
among isolates grown on boscalid amended plates at $P=0.05$.

Table 2. Mycelial growth ratio summary statistics of 58 isolates of Alternaria alternata and 50 isolates of A. solani on media amended with azoxystrobin and boscalid

y Effect size was calculated as Cohen's $d$, where $d=\left(m^{2}-m^{1}\right) / s_{\text {pooled }}$.

z $95 \%$ Confidence intervals for Cohen's $d$ were calculated as $[d]=\sqrt{(}\left(n^{1}+n^{2}\right) /\left(n^{1} * n^{2}\right)+d^{2} / 2\left(n^{1}+n^{2}\right)$ and $[d+(1.96 * \sigma[d]), d-(1.96 * \sigma[d]$. 
boscalid plates was not significantly different than of $A$. solani isolates collected in $2010(P=0.1, P=0.5$, respectively), the mean mycelial growth ratio and percent spore germination of $A$. alternata isolates collected in 2011 were significantly less $(P<0.0001)$ than for A. solani isolates collected in 2011. Mean mycelial growth ratio for $A$. alternata isolates was 0.14 and percent spore germination was 0.53 . Mean mycelial growth ratio for $A$. solani isolates was 0.40 and percent spore germination was 0.97 .

Mycelial growth ratio of $A$. alternata collected on azoxystrobin was significantly less $(P=0.04)$ between isolates collected in 2010 than in 2011 (Table 3). However, percent spore germination did not significantly differ $(P=0.12)$ between isolates of A. alternata collected in 2010 and 2011. Mycelial growth ratio and percent spore germination did not differ $(P=0.39, P=0.67$, respectively) on boscalid for isolates of $A$. alternata collected in 2010 and 2011.

Mycelial growth ratio and percent spore germination of $A$. solani on azoxystrobin did not significantly differ $(P=0.7, P=0.52$, respectively) between isolates collected in 2010 and 2011 (Table 3 ). Mycelial growth ratio and percent spore germination of $A$. solani on boscalid was significantly less $(P<0.0001)$ for isolates collected in 2010 than isolates collected in 2011. Percent spore germination exhibited a more reduced response to fungicides than did mycelial growth ratio for both fungicides.

Fungicide concentration analysis. Percent spore germination of the three selected isolates of A. alternata at $1 \mu \mathrm{g} / \mathrm{ml}$ azoxystrobin was not significantly different $(P=0.98)$ than that of a single isolate of $A$. solani (Table 4). Percent spore germination of
A. alternata was significantly greater than those of $A$. solani at 10 and $100 \mu \mathrm{g} / \mathrm{ml}$ azoxystrobin $(P=0.05, P=0.0009$, respectively). Percent spore germination of A. alternata were 0.87 and 0.83 at 10 and $100 \mu \mathrm{g} / \mathrm{ml}$ azoxystrobin, respectively, and 0.68 and 0.50 for $A$. solani, respectively. Percent spore germination of A. alternata and A. solani did not significantly decrease $(P=0.79, P=0.06)$ as azoxystrobin concentrations increased.

Percent spore germination of A. alternata was significantly less than that of $A$. solani at $0.5,5$, and $50 \mu \mathrm{g} / \mathrm{ml}$ boscalid $(P=0.05, P$ $=0.002, P=0.008$ ) (Table 4). Percent spore germination values at $0.5,5$, and $50 \mu \mathrm{g} / \mathrm{ml}$ boscalid were $0.82,0.76$, and 0.69 , respectively, for A. alternata and were $0.96,0.92$, and 0.94 , respectively, for A. solani. Percent spore germination of A. alternata and A. solani did not decrease as boscalid concentrations increased $(P=$ $0.27, P=0.05$, respectively).

Percent spore germination of all three A. alternata isolates exhibited resistance at 1,10 , and $100 \mu \mathrm{g} / \mathrm{ml}$ azoxystrobin only, whereas only mycelial growth of isolate AA10_28 exhibited resistance at the three concentrations (Table 5). Mycelial growth ratios of isolates AA10_06 and AA10_42 were moderately sensitive at $100 \mu \mathrm{g} / \mathrm{ml}$, but exhibited sensitivity at 1 and $10 \mu \mathrm{g} / \mathrm{ml}$. The results of the spore germination assay were consistent with the mycelial growth ratio results at the threshold concentration for isolates AA10_28 and AA10_42. Percent spore germination of isolate AS10_95 exhibited sensitivity at $100 \mu \mathrm{g} / \mathrm{ml}$ but not at 1 or $10 \mu \mathrm{g} / \mathrm{ml}$ azoxystrobin. Percent spore germination of isolate AS11_52 exhibited resistance at all concentrations of azoxystrobin,

Table 3. Mycelial growth ratio and percent spore germination on azoxystrobin and boscalid amended media of 58 isolates of Alternaria alternata and 50 isolates of A. solani collected in 2010 and $2011^{\mathrm{y}}$

\begin{tabular}{|c|c|c|c|c|c|c|}
\hline & \multicolumn{3}{|c|}{ Azoxystrobin + SHAM } & \multicolumn{3}{|c|}{ Boscalid + SHAM } \\
\hline & 2010 & 2011 & $P$ value & 2010 & 2011 & $P$ value \\
\hline \multicolumn{7}{|c|}{ Mycelial growth ratio } \\
\hline A. alternata & $0.36 \mathrm{a}^{* \mathrm{z}}$ & $0.33 \mathrm{a}$ & 0.04 & $0.20 \mathrm{a}$ & $0.14 \mathrm{a}$ & 0.39 \\
\hline A. solani & $0.20 \mathrm{~b}$ & $0.21 \mathrm{~b}$ & 0.7 & $0.20 \mathrm{a}^{*}$ & $0.40 \mathrm{~b}$ & $<0.0001$ \\
\hline$P$ value & $<0.0001$ & $<0.0001$ & & 0.1 & $<0.0001$ & \\
\hline \multicolumn{7}{|c|}{ Percent spore germination } \\
\hline A. alternata & $0.73 \mathrm{a}$ & $0.56 \mathrm{a}$ & 0.12 & $0.58 \mathrm{a}$ & $0.53 \mathrm{a}$ & 0.67 \\
\hline A. solani & $0.50 \mathrm{~b}$ & $0.44 \mathrm{a}$ & 0.52 & $0.50 \mathrm{a}^{*}$ & $0.97 \mathrm{~b}$ & $<0.0001$ \\
\hline$P$ value & 0.04 & 0.22 & & 0.50 & $<0.0001$ & \\
\hline
\end{tabular}

y Values with the same letter within a column for each variable are not significantly different at $P=0.05$.

$\mathrm{z} *$ indicates significance across a row at $P=0.05$.

Table 4. Percent spore germination of Alternaria alternata and A. solani on three concentrations of azoxystrobin and boscalid amended media

\begin{tabular}{|c|c|c|c|c|c|c|c|c|}
\hline \multirow[b]{2}{*}{ Species } & \multicolumn{4}{|c|}{ Azoxystrobin concentration $\mu \mathrm{g} / \mathrm{ml}$} & \multicolumn{4}{|c|}{ Boscalid concentration $\mu \mathrm{g} / \mathrm{ml}$} \\
\hline & 1 & 10 & 100 & $P$ value & 0.5 & 5 & 50 & $P$ value \\
\hline A. alternata & $0.83 \mathrm{a}^{\mathrm{z}}$ & $0.87 \mathrm{a}$ & $0.83 \mathrm{a}$ & 0.79 & $0.82 \mathrm{a}$ & $0.76 \mathrm{a}$ & $0.69 \mathrm{a}$ & 0.27 \\
\hline A. solani & $0.83 \mathrm{a}$ & $0.68 \mathrm{~b}$ & $0.50 \mathrm{~b}$ & 0.06 & $0.96 \mathrm{~b}$ & $0.92 \mathrm{~b}$ & $0.94 \mathrm{~b}$ & 0.05 \\
\hline$P$ value & 0.98 & 0.05 & 0.0009 & & 0.05 & 0.002 & 0.008 & \\
\hline
\end{tabular}

${ }^{\mathrm{z}}$ Values with the same letter within a column are not significantly different at $P=0.05$.

Table 5. Characterization of fungicide resistance to azoxystrobin and boscalid of two Alternaria solani and three A. alternata isolates on three fungicide concentrations using percent spore germination and mycelial growth ratios

\begin{tabular}{|c|c|c|c|c|c|c|c|c|c|c|c|c|}
\hline \multirow{3}{*}{$\begin{array}{c}\text { Species } \\
\text { Isolate }\end{array}$} & \multicolumn{6}{|c|}{ Percent spore germination } & \multicolumn{6}{|c|}{ Mycelial growth ratio } \\
\hline & \multicolumn{3}{|c|}{ A concentration $(\mu \mathrm{g} / \mathrm{ml})^{\mathrm{y}}$} & \multicolumn{3}{|c|}{ B concentration $(\mu \mathrm{g} / \mathrm{ml})^{\mathrm{z}}$} & \multicolumn{3}{|c|}{ A concentration $(\mu \mathrm{g} / \mathrm{ml})^{y}$} & \multicolumn{3}{|c|}{ B concentration $(\mu \mathrm{g} / \mathrm{ml})^{\mathrm{z}}$} \\
\hline & 1 & 10 & 100 & 0.5 & 5 & 50 & 1 & 10 & 100 & 0.5 & 5 & 50 \\
\hline \multicolumn{13}{|l|}{ A. solani } \\
\hline AS10_95 & 0.77 & 0.51 & $0.29(\mathrm{~S})$ & 0.98 & 0.80 & $0.97(\mathrm{R})$ & 0.15 & 0.1 & $0.12(\mathrm{~S})$ & 1.61 & 0.92 & $0.7(\mathrm{R})$ \\
\hline AS11_52 & 0.96 & 0.93 & $0.72(\mathrm{R})$ & 0.91 & 0.88 & $0.92(\mathrm{R})$ & 0.95 & 0.38 & $0.21(\mathrm{~S})$ & 0.98 & 0.59 & $0.35(\mathrm{~S})$ \\
\hline \multicolumn{13}{|l|}{ A. alternata } \\
\hline AA10_28 & 0.87 & 0.78 & $0.67(\mathrm{R})$ & 0.92 & 0.81 & $0.88(\mathrm{R})$ & 0.82 & 0.85 & $0.52(\mathrm{MR})$ & 1.00 & 0.84 & $0.73(\mathrm{R})$ \\
\hline AA10 06 & 0.75 & 0.92 & $0.93(\mathrm{R})$ & 0.80 & 0.70 & $0.70(\mathrm{R})$ & 0.99 & 0.77 & $0.47(\mathrm{~S})$ & 1.14 & 0.75 & $0.66(\mathrm{R})$ \\
\hline AA10_42 & 0.90 & 0.90 & $0.90(\mathrm{R})$ & 0.81 & 0.45 & $0.68(\mathrm{R})$ & 0.97 & 0.69 & $0.44(\mathrm{~S})$ & 0.70 & 0.33 & $0.23(\mathrm{~S})$ \\
\hline
\end{tabular}

${ }^{y}$ Azoxystrobin amended media.

${ }^{\mathrm{z}}$ Boscalid amended media. 
which was inconsistent with the assay at a threshold concentration, where both isolates of $A$. solani exhibited sensitivity to azoxystrobin. Mycelial growth of isolate AS10_95 exhibited sensitivity to azoxystrobin at all three concentrations, whereas isolate AS11_52 exhibited sensitivity at 10 and $100 \mu \mathrm{g} / \mathrm{ml}$.

Spore germination and mycelial growth ratios of A. alternata isolates AA10_28 and AA10_06 exhibited resistance at all three boscalid concentrations (Table 5). Spore germination of AA10_42 exhibited resistance at 0.5 and $50 \mu \mathrm{g} / \mathrm{ml}$ boscalid, but mycelial growth exhibited sensitivity at 5 and $50 \mu \mathrm{g} / \mathrm{ml}$. Percent spore germination of A. solani isolates AS11_52 and AS10_95 exhibited resistance to boscalid at all three concentrations. Mycelial growth of AS10_95 also exhibited resistance at all three concentrations; however, mycelial growth of AS11_52 exhibited sensitivity at 50 $\mu \mathrm{g} / \mathrm{ml}$. While this result was consistent at the threshold concentration for isolate AS11_52, it was inconsistent with the results at the threshold concentration for isolate AS10_95.

Significant differences in mycelial growth were observed among three trials to characterize fungicide resistance at three concentrations, so trial data were analyzed separately (Table 6). Mycelial growth ratios were significantly greater for A. alternata than for $A$. solani in two of three trials at 1,10 , and $100 \mu \mathrm{g} / \mathrm{ml}$ azoxystrobin $(P$ $<0.05)$. Mycelial growth ratios for A. alternata and A. solani significantly decreased $(P<0.05)$ as concentrations of azoxystrobin increased in all three trials. Mycelial growth ratios for A. alternata were not significantly different $(P>0.05)$ than those of $A$. solani in two of three trials at 0.5 and $5 \mu \mathrm{g} / \mathrm{ml}$ boscalid. Mycelial growth ratios for $A$. alternata were not significantly different $(P>0.05)$ than A. solani in all three trials at $50 \mu \mathrm{g} / \mathrm{ml}$ boscalid. Mycelial growth ratios for A. alternata did not change as concentrations of boscalid increased in two of three trials. However, growth ratios for A. solani significantly decreased $(P<0.05)$ in two of three trials.

\section{Discussion}

Wide ranges in mycelial growth ratios for A. solani and A. alternata were observed at the selected threshold concentrations for azoxystrobin and boscalid. Most isolates of $A$. solani and A. alternata were sensitive to both fungicides, with some isolates exhibiting moderate resistance to azoxystrobin and resistance to boscalid. Ten of $50(20 \%)$ isolates of A. solani and 2 of $58(3.4 \%)$ isolates of A. alternata exhibited resistance to boscalid, whereas 3 of 58 (5.2\%) isolates of A. alternata exhibited resistance to azoxystrobin. Resistance can quickly spread through a region, especially when fungicides with the same mode of action are repetitiously applied. For example, resistance to metalaxyl by Pseudoperonospora cubensis was found in Israel after only 3 years of use on cucumbers (24). Moreover, resistance to QoI fungicides by Blumeria graminis was discovered in wheat only 2 years after their initial use (25). The sharp increase in resistance to boscalid observed in isolates of A. solani between 2010 and 2011 in this study also demonstrates how quickly resistance to fungicides can increase. The increase of moderately sensitive to resistant A. alternata isolates of azoxy- strobin appears to be developing less rapidly in the Columbia Basin. However, the presence of these isolates indicates that the potential for a resistant population to build up exists.

The rate at which fungicide resistance develops in a population is based on three criteria: initial frequency of resistant isolates, infection rates of fungicide resistant and sensitive isolates, and the infection rate of the fungicide resistant isolates relative to sensitive isolates (17). The potential rate at which azoxystrobin and boscalid resistance could develop in both Alternaria species is high in the Columbia Basin because all three factors apply to both populations. Even though the frequency of resistant isolates may be initially moderate, repeated applications of azoxystrobin and boscalid will likely select for resistant genotypes. Alternaria spp. produce large numbers of conidia throughout the growing season, which may exponentially increase the frequency of potential resistant isolates. Conidia of Alternaria species are wind dispersed, and inoculum of resistant isolates can be disseminated over various distances (5). Fungicide resistance would be selected for with the use of narrow spectrum fungicides without tank mixing and-alternating with broad spectrum fungicides. In this study, azoxystrobin resistant isolates of $A$. alternata used in the fungicide concentration assay were collected from fields that had been regularly treated with azoxystrobin. The isolate of $A$. solani that exhibited resistance to boscalid was collected from a field that had been untreated, which indicates that resistant isolates may be originally present in populations at low frequencies. This was also observed in populations of A. alternata on pistachio (1). Additionally, the large host range of A. alternata (26) complicates the process of reducing the frequency of resistant isolates due to the selection of resistant isolates through fungicide applications made for other crops in the region.

The strobilurin fungicides are effective inhibitors of spore germination (4). This is supported by studies on the differential response of spore germination and mycelial growth of Venturia inaequalis, Phytophthora spp., and A. alternata isolated from Red Delicious apple $(10,16,20,24)$ in the presence of these fungicides. However, azoxystrobin can collapse mycelia and inhibit further infection by the pathogens. The dual action allows for growers in the Columbia Basin to apply products as a preventative or a curative, thereby reducing disease severity. Assessing fungicide resistance of both pathogen infection and colonization will help in the development of more effective disease management programs.

In this study, spore germination of A. solani and A. alternata was affected less than mycelial growth at the threshold concentration by azoxystrobin and boscalid. Percent spore germination of $A$. solani and A. alternata at a threshold concentration was proportionally greater than mycelial growth ratios. These results were also observed at higher fungicide concentrations for both azoxystrobin and boscalid. Mycelial growth ratio results were similar to those of the percent spore germination at the lowest concentrations of 1 and $0.5 \mu \mathrm{g} / \mathrm{ml}$ of azoxystrobin and boscalid. This indicates that these low concentrations of fungicides are ineffective at

Table 6. Mycelial growth ratios for Alternaria alternata and A. solani on three concentrations of azoxystrobin and boscalid amended media

\begin{tabular}{|c|c|c|c|c|c|c|c|c|}
\hline \multirow[b]{2}{*}{ Trial } & \multicolumn{4}{|c|}{ Azoxystrobin concentration $\mu \mathrm{g} / \mathrm{ml}$} & \multicolumn{4}{|c|}{ Boscalid concentration $\mu \mathrm{g} / \mathrm{ml}$} \\
\hline & 1 & 10 & 100 & $P$ value & 0.5 & 5 & 50 & $P$ value \\
\hline \multicolumn{9}{|l|}{ Trial 1} \\
\hline A. alternata & $0.8 \mathrm{a}^{\mathrm{z}}$ & $0.4 \mathrm{a}$ & $0.4 \mathrm{a}$ & 0.01 & $0.7 \mathrm{a}$ & $0.3 \mathrm{a}$ & $0.2 \mathrm{a}$ & 0.04 \\
\hline A. solani & $0.3 \mathrm{~b}$ & $0.2 \mathrm{~b}$ & $0.1 \mathrm{~b}$ & 0.03 & $0.8 \mathrm{a}$ & $0.8 \mathrm{~b}$ & $0.2 \mathrm{a}$ & 0.01 \\
\hline$P$ value & $<0.0001$ & 0.001 & 0.004 & & 0.8 & 0.04 & 0.8 & \\
\hline \multicolumn{9}{|l|}{ Trial 2} \\
\hline A. alternata & $0.8 \mathrm{a}$ & $0.8 \mathrm{a}$ & $0.4 \mathrm{a}$ & $<0.0001$ & $0.9 \mathrm{a}$ & $0.3 \mathrm{a}$ & $0.5 \mathrm{a}$ & 0.43 \\
\hline A. solani & $0.7 \mathrm{a}$ & $0.2 \mathrm{~b}$ & $0.2 \mathrm{a}$ & 0.01 & $1.3 \mathrm{~b}$ & $0.1 \mathrm{a}$ & $0.5 \mathrm{a}$ & 0.22 \\
\hline$P$ value & 0.08 & $<0.0001$ & 0.08 & & 0.04 & 0.25 & 0.84 & \\
\hline \multicolumn{9}{|l|}{ Trial 3} \\
\hline A. alternata & $1.1 \mathrm{a}$ & $1 \mathrm{a}$ & $0.7 \mathrm{a}$ & $<0.0001$ & $0.9 \mathrm{a}$ & $0.9 \mathrm{a}$ & $0.7 \mathrm{a}$ & 0.3 \\
\hline A. solani & $0.7 \mathrm{~b}$ & $0.3 \mathrm{~b}$ & $0.2 \mathrm{~b}$ & 0.01 & $1.2 \mathrm{a}$ & $1 \mathrm{a}$ & $0.5 \mathrm{a}$ & 0.02 \\
\hline$P$ value & 0.008 & $<0.0001$ & 0.0002 & & 0.4 & 0.9 & 0.3 & \\
\hline
\end{tabular}

${ }^{\mathrm{z}}$ Values with the same letter within a column for a trial are not significantly different at $P=0.05$. 
reducing infection and colonization by the pathogen and that a minimum of $100 \mu \mathrm{g} / \mathrm{ml}$ of azoxystrobin and $50 \mu \mathrm{g} / \mathrm{ml}$ of boscalid are needed for management.

One possibility for the differential response between mycelial growth and spore germination in this study versus other studies may be due to the use of SHAM in fungicide-amended plates. SHAM had no effect on the spore germination of A. solani (21), A. alternata (18), and Ascochyta rabiei (24). However, SHAM had an inhibitory effect on mycelial growth of A. alternata isolated from citrus on plates amended with azoxystrobin. The sensitivity of $A$. alternata to fungicides was not altered by SHAM (18). Steinfeld et al. examined the effects of cellular respiration inhibitors of $V$. inaequalis and also found mycelia to be more sensitive than spore germination, particularly with the addition of SHAM (28). SHAM effectively inhibits the use of an alternate pathway for cellular respiration when QoIs block electron transport between cytochrome $b$ and $c$. This pathway is active on artificial media (18). While the alternative oxidase pathway was not utilized by mycelia of $V$. inaequalis (28), the decreased sensitivity of A. alternata mycelia to azoxystrobin may be due to the omission of SHAM from the media. Trends in resistance observed in mycelial growth were typically observed in spore germination assays; however, using mycelial growth to determine effective concentration rates may be underestimating the rates of product required for adequate disease management.

The use of $P$ values to determine whether there were statistical differences between treatment and control is common. Effect size, which is often used in ecological studies and social sciences, has not been commonly reported in biological research. This statistic quantifies biological significance by comparing the distributions of the treatment versus control. The $95 \%$ confidence interval provides the range in which the population's true value exists (19). Values of 0.8 and greater indicate large effects or small overlap of distributions. Effect sizes for A. solani and A. alternata isolates at the threshold concentrations were greater than 0.8 for both fungicide treatments, indicating that overall, azoxystrobin and boscalid had a significant effect in reducing mycelial growth in populations of $A$. solani and A. alternata in the Columbia Basin. Continuous use of these fungicides without tank mixing and alternating applications with broad spectrum products will contribute to the growth of resistant isolates in the population.

Resistance to azoxystrobin and boscalid in the A. alternata population and to boscalid in the A. solani population are present in the Columbia Basin. Resistance to boscalid by A. solani appears to be rapidly increasing, while resistance to azoxystrobin by $A$. alternata may develop more slowly. Screening isolates at the threshold concentrations using mycelial growth was an effective means for detecting and capturing the range of fungicide resistance in the Columbia Basin. Mycelial growth sensitivity of Alternaria isolates to fungicides was consistent with spore germination sensitivity for three of five isolates for azoxystrobin and boscalid. Spore germination assays should continue to be the preferred means of testing for resistance in vitro due to the possible inhibition of mycelial growth by SHAM. Otherwise, fungicide rates based on mycelial growth assays may underestimate the effective rate for management. Spore germination assays should also be the primary assay in assessing effective rates, since inhibition of spore germination is a major step in avoiding infection and epidemic development.

\section{Acknowledgments}

We thank Thomas F. Cummings for technical assistance in analyzing data and Mark Pavek and George Vandemark for critical reviews of the manuscript. We also thank Don Drader, Mike Hubbard, and Jeff Miller for providing us with potato leaf samples. We appreciate support from the Washington State Potato Commission for partial funding of this study. PPNS no. 0636, Department of Plant Pathology, College of Agricultural, Human, and Natural Resource Sciences Agricultural Research Center, Hatch Project No. WNPO 0678, Washington State University, Pullman, WA 99164-6430.

\section{Literature Cited}

1. Avenot, H. F., and Michailides, T. J. 2007. Resistance to boscalid fungicide in Alternaria alternata isolates from pistachio in California. Plant Dis.
91:1345-1350.

2. Avenot, H. F., and Michailides, T. J. 2010. Progress in understanding molecular mechanisms and evolution of resistance to succinate dehydrogenase inhibiting (SDHI) fungicides in phytopathogenic fungi. Crop Prot. 29:643-651.

3. Avila-Adame, C., Olaya, G., and Köller, W. 2003. Characterization of Colletotrichum graminicola isolates resistant to strobilurin-related QoI fungicides. Plant Dis. 87:1426-1432.

4. Bartlett, D. W., Clough, J. M., Godwin, J. R., Hall, A. A., Hamer, M., and Parr-Dobrzanski, B. 2002. The strobilurin fungicides. Pest Manag. Sci. 58:649-662.

5. Bashan, Y., Levanony, H., and Or, R. 1991. Wind dispersal of Alternaria alternata, a cause of leaf blight of cotton. J. Pathol. 133:225-238.

6. Christ, B., and Maczuga, S. 1989. The effect of fungicide schedules and inoculum levels on early blight severity and yield of potato. Plant Dis. 73:695-698.

7. Cohen, J. 1988. Statistical Power Analysis for the Behavioral Sciences. Psychology Press.

8. Delp, C. J. 1980. Coping with resistance to plant disease. Plant Dis. 64:652-657.

9. Fairchild, K. L., Miles, T. D., and Wharton, P. S. 2013. Assessing fungicide resistance in populations of Alternaria in Idaho potato fields. Crop Prot. 49:31-39.

10. Godwin, J. R., Anthony, V. M., Clough, J. M., and Godfrey, C. R. A. 1992. ICIA 5504: A novel, broad spectrum, systemic B-methoxyacrylate fungicide. Proc. Br. Crop Prot. Con. Pests Dis. 10:435-442.

11. Johnson, D. A., Cummings, T. F., Ghanem, R. A., and Alldredge, J. R. 2009 Association of solar irradiance and days of precipitation with incidence of potato late blight in the semiarid environment of the Columbia Basin. Plant Dis. 93:272-280.

12. Johnson, D. A., Cummings, T. F., and Hamm, P. B. 2000. Cost of fungicides used to manage potato late blight in the Columbia Basin: 1996 to 1998 . Plant Dis. 84:399-402.

13. Karaoglanidis, G., Luo, Y., and Michailides, T. 2011. Competitive ability and fitness of Alternaria alternata isolates resistant to QoI fungicides. Plant Dis. 95:178-182.

14. Kim, Y., and Xiao, C. 2010. Resistance to pyraclostrobin and boscalid in populations of Botrytis cinerea from stored apples in Washington State. Plant Dis. 94:604-612.

15. Ma, Z., Felts, D., and Michailides, T. J. 2003. Resistance to azoxystrobin in Alternaria isolates from pistachio in California. Pestic. Biochem. Physiol 77:66-74.

16. Matheron, M., and Porchas, M. 2000. Impact of azoxystrobin, dimethomorph, fluazinam, fosetyl-Al, and metalaxyl on growth, sporulation, and zoospore cyst germination of three Phytophthora spp. Plant Dis. 84:454-458.

17. Miyamoto, T., Ishii, H., and Tomita, Y. 2010. Occurrence of boscalid resistance in cucumber powdery mildew in Japan and molecular characterization of the iron-sulfur protein of succinate dehydrogenase of the causal fungus. J. Gen. Plant Pathol. 76:261-267.

18. Mondal, S., Bhatia, A., Shilts, T., and Timmer, L. 2005. Baseline sensitivities of fungal pathogens of fruit and foliage of citrus to azoxystrobin, pyraclostrobin, and fenbuconazole. Plant Dis. 89:1186-1194.

19. Nakagawa, S., and Cuthill, I. C. 2007. Effect size, confidence interval an statistical significance: A practical guide for biologists. Biol. Rev. 82:591-605.

20. Olaya, G., Zheng, D., and Köller, W. 1998. Differential responses of germinating Venturia inaequalis conidia to kresoxim-methyl. Pestic. Sci. 54:230-236.

21. Pasche, J., Wharam, C., and Gudmestad, N. 2004. Shift in sensitivity of Alternaria solani in response to QoI fungicides. Plant Dis. 88:181-187.

22. Powelson, M., and Rowe, R. 2008. Managing diseases caused by seedborne and soilborne fungi and fungus-like pathogens. Potato Health Management 2183-2195

23. Powelson, M. L., and Rowe, R. C. 1993. Biology and management of early dying of potatoes. Annu. Rev. Phytopathol. 31:111-126.

24. Reuveni, M., Eyal, H., and Cohen, Y. 1980. Development of resistance to metalaxyl in Pseudoperonospora cubensis. Plant Dis. 64:1108-1109.

25. Rosenzweig, N., Olaya, G., Atallah, Z., Cleere, S., Stanger, C., and Stevenson, W. 2008. Monitoring and tracking changes in sensitivity to azoxystrobin fungicide in Alternaria solani in Wisconsin. Plant Dis. 92:555-560.

26. Rotem, J. 1994. The genus Alternaria: Biology, Epidemiology, and Pathogenicity. American Phytopathological Society, St. Paul, MN.

27. Shtienberg, D., Blachinsky, D., Ben-Hador, G., and Dinoor, A. 1996. Effects of growing season and fungicide type on the development of Alternaria solani and on potato yield. Plant Dis. 80:994-998.

28. Steinfeld, U., Sierotzki, H., Parisi, S., Poirey, S., and Gisi, U. 2001 Sensitivity of mitochondrial respiration to different inhibitors in Venturia inaequalis. Pest Manag. Sci. 57:787-796.

29. Stevenson, W., Kirk, W., and Atallah, Z. 2007. Management of foliar disease, early blight, late blight and white mold. Potato Health Management. 209-222.

30. U.S. Dep. Agric. C.N.A.S. 2014. Crop Production 2013 Summary. Online: http://www.nass.usda.gov

31. Wise, K., Bradley, C., Pasche, J., and Gudmestad, N. 2009. Resistance to QoI fungicides in Ascochyta rabiei from chickpea in the Northern Great Plains. Plant Dis. 93:528-536. 